\title{
Oestrogenic sensitivity of rat uterine secretion
}

\author{
G. Meglioli \\ Research Department, Pharmaceuticals Division, CIBA-GEIG Y Ltd, Basle, Switzerland
}

\begin{abstract}
Summary. Ovariectomized adult rats with closed uteri were treated for 7 days with different oral and s.c. doses of oestradiol, oestrone, oestriol and ethinyl oestradiol. All treatments elicited the production of uterine fluid and the potencies of oestrogens were related to the amount of fluid secreted. Ethinyl oestradiol and oestradiol displayed similar activity when given s.c. A daily dose of $0.003 \mathrm{mg}$ oestradiol $/ \mathrm{kg}$ resulted in about $700 \mathrm{mg}$ fluid. Oestrone was 3-10 times and oestriol about 100 times less active. Orally, ethinyl oestradiol was the most potent substance and $700 \mathrm{mg}$ secretion was obtained with a dose of $0.03 \mathrm{mg} / \mathrm{kg}$ daily. Oestradiol was about 30 times, oestrone about 100 times and oestriol 50 times less active than ethinyl oestradiol by this route. The viscosity of the secretion was unaffected, remaining between 1.6 and $2.4 \mathrm{cP}$. The $\mathrm{pH}$ of the fluid did not change, but that of the uterine lumen diminished slightly. These effects of oestrogens were associated with an increase in the weight of the empty uterus and a decrease in body weight.
\end{abstract}

\section{Introduction}

In rats with a regular 4-day oestrous cycle, the secretion of uterine fluid begins in the early hours of the day of pro-oestrus, generally around 03.00 hours and continues until about 04.00 hours on the day of oestrus (Meglioli, 1974). This secretion may be attributable to the secretion of oestrogens by the ovaries, since fluid accumulates in the closed uteri of spayed rats treated with oestradiol (Ringler, 1961 ; Armstrong, 1968; Meglioli, Krähenbühl \& Desaulles, 1969). Most workers have used oestradiol to demonstrate this activity, and little has been published about the sensitivity of the secretory response of the endometrium to other oestrogens.

In the experiments described in this paper, the fluid secretion evoked by some natural oestrogens (oestradiol, oestrone and oestriol) and by ethinyl oestradiol was investigated.

\section{Materials and Methods}

Adult female rats (Ivanovas, Kisslegg, Germany) of $160 \mathrm{~g}$ wt were used. Under ether anaesthesia, the ovaries were removed and the proximal and distal ends of the uterus were closed by electrocauterization so that the secretions of the uterus could be collected. Care was taken to leave the regional blood supply intact. Beginning on the day after the operation, groups of 10 animals were treated with oestradiol, oestrone, oestriol or ethinyl oestradiol for 7 days in daily doses between $0.003 \mathrm{mg} / \mathrm{kg}$ and $1 \mathrm{mg} / \mathrm{kg}$ (s.c. in sesame oil) and $3 \mathrm{mg} / \mathrm{kg}$ (orally in $25 \%$ ethyl alcohol). Rats treated with the solvent only acted as controls. As a prophylactic measure the animals also received s.c. injections $6000 \mathrm{U}$ penicillin and $10 \mathrm{mg}$ streptomycin daily for 7 days after the operation. The rats were killed $24 \mathrm{hr}$ after the last hormone dose. The uteri were removed and the uterine fluid was collected. Bacteriological examinations of the fluid were made and any infected specimens were discarded.

The quantity of secretion was found from the difference in the weight of the uterus before and after fluid aspiration. The $\mathrm{pH}$ of the uterine lumen and the $\mathrm{pH}$ and viscosity of the uterine secretion were measured by the techniques described by Meglioli et al. (1969). 


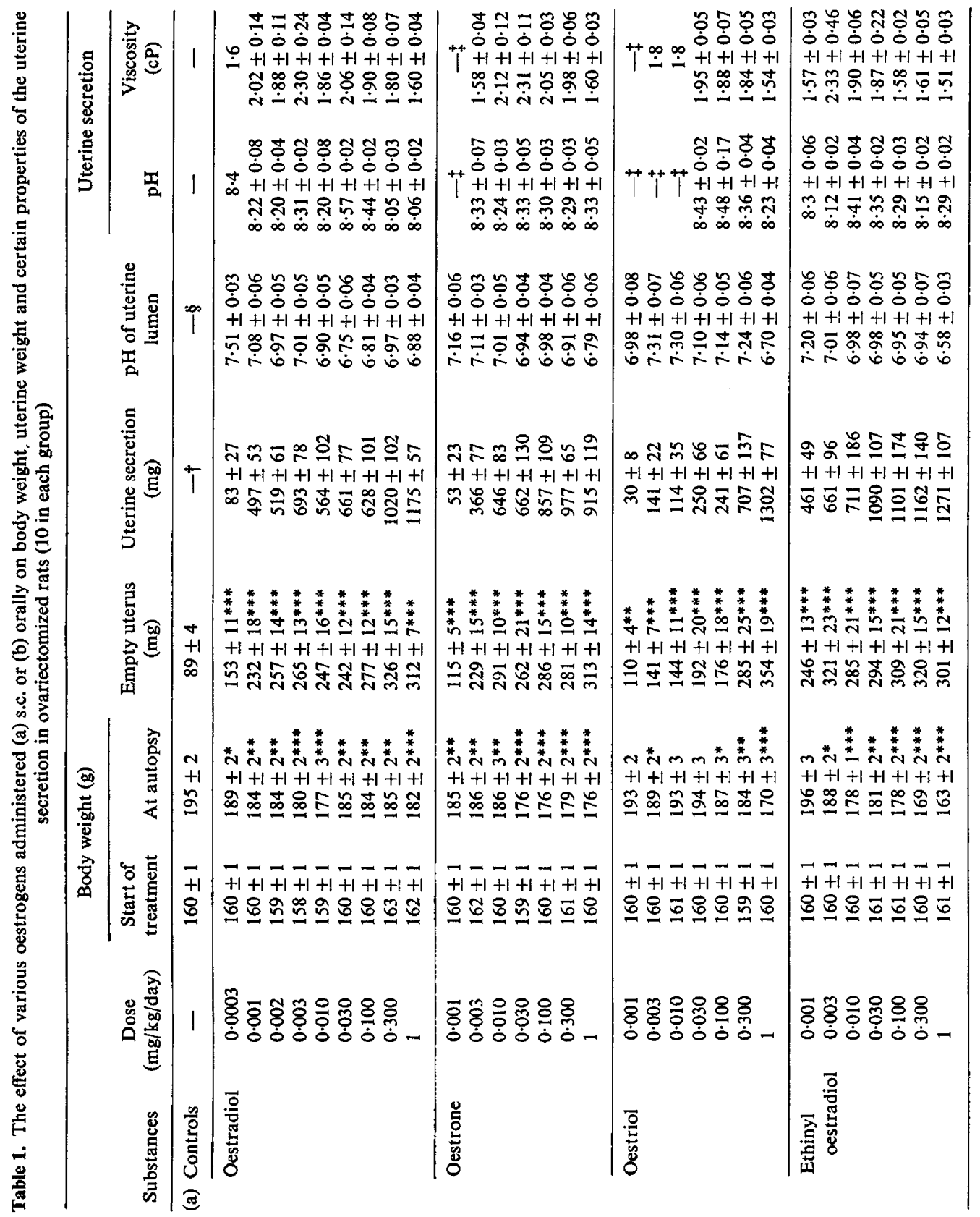




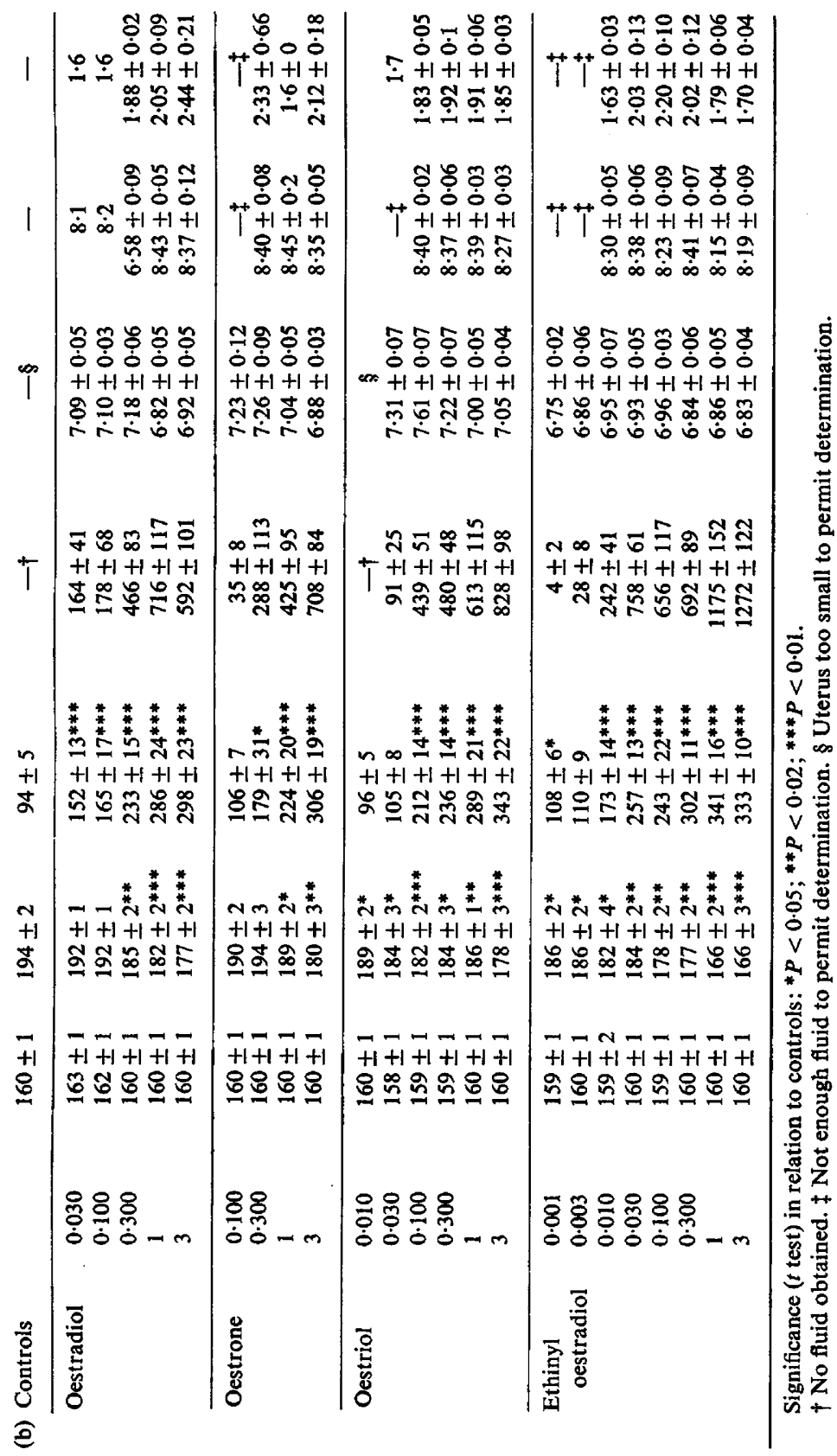




\section{Results}

The results are given in Table 1. In the control rats no secretion accumulated, and as the uteri in these animals were small, the $\mathrm{pH}$ of the lumen could not be determined. All the oestrogens tested induced secretion, whether they were administered parenterally or orally.

Oestradiol proved to be the most active of the three natural oestrogens, very low doses administered s.c. producing a relatively marked degree of secretion. The maximum response was obtained with a dose of $0.003 \mathrm{mg} / \mathrm{kg}$ and more copious secretion was elicited only by unphysiologically high doses. Oestrone appeared to be 3-10 times less potent than oestradiol and oestriol was about 100 times less potent than oestradiol. Ethinyl oestradiol, however, induced a very marked response: the effect of low doses was similar to that of oestradiol, but that of doses between 0.01 and $0.1 \mathrm{mg} / \mathrm{kg}$ was much greater.

As expected, the substances tested were much less active when given orally. The difference was very marked for oestradiol and oestrone and only slightly less for oestriol (Table 1). In order to obtain a quantity of 600-700 mg uterine fluid, the volume taken as a standard for comparison, daily doses of $1 \mathrm{mg}$ oestradiol $/ \mathrm{kg}, 2 \mathrm{mg}$ oestriol $/ \mathrm{kg}$ (to assume a linear dose-response relationship) and $3 \mathrm{mg}$ oestrone $/ \mathrm{kg}$ were required. Oestriol appeared to be more active than oestrone when given by mouth. Ethinyl oestradiol was again more potent than the natural oestrogens although about 10 times less active when given orally; a dose of $0.03 \mathrm{mg} / \mathrm{kg}$ led to the accumulation of more than $700 \mathrm{mg}$ fluid.

The $\mathrm{pH}$ of the secretion was alkaline after treatment with low doses of the oestrogens. No notable changes were observed in response to higher doses, except perhaps for a slight tendency for the $\mathrm{pH}$ to diminish after treatment with oestradiol s.c. and ethinyl oestradiol by mouth. The $\mathrm{pH}$ of the uterine lumen diminished in response to increasing oral and s.c. doses of all the oestrogens tested, especially ethinyl oestradiol.

The weight of the empty uterus was increased by treatment with all the oestrogens tested, to an extent closely corresponding to their effects on the volume of fluid secreted. Body weight was invariably reduced, most markedly so after the administration of high doses.

\section{Discussion}

The results of these investigations show that the secretory response of the endometrium to parenteral and oral treatment with the three natural oestrogens, oestradiol, oestrone and oestriol, and with ethinyl oestradiol differs in degree. Despite the differences in the experimental conditions, the results on the relative potencies of the oestrogens are in agreement with the findings of Conner \& Miller (1973) who studied the effects of parenteral administration of natural oestrogens for 3 days. In their investigations, however, oestriol failed to produce any secretion, whereas in ours some fluid accumulated in the uterus in response to high doses.

Unlike progestagens (Meglioli, Kalvoda \& Desaulles, 1973), oestrogens, even in high, nonphysiological doses, did not significantly modify the viscosity and $\mathrm{pH}$ of the secretion, and the increase in the acidity of the uterine lumen observed after oestrogen treatment was much less pronounced than that caused by the administration of progesterone (Meglioli \& Desaulles, 1973).

The relative effects of the oestrogens tested on the weight of the empty uterus after parenteral administration were comparable with those observed by other authors (Velardo, 1951; Conner \& Miller, 1973). However, the classical response of the uterus to oestriol (Huggins \& Jensen, 1955) that is apparent after parenteral treatment tended to be absent upon oral administration. It is possible that under the particular conditions obtained in this study (adult animals with ligated uteri) oestriol exerts a full oestrogenic effect. The retardation of body weight gain caused by the administration of high doses of oestrogens is well known (Zondek, 1936; Josimovich, Mintz \& Finster, 1967; Jones, 1971).

The secretory response observed under the experimental conditions described in this paper might serve as the basis for a useful bioassay of oestrogenic substances. 
The constructive criticisms of Dr Charles Krähenbühl are gratefully acknowledged.

\section{References}

ARMSTRONG, D.T. (1968) Hormonal control of uterine lumen fluid retention in the rat. Am. J. Physiol. 214, 764-771.

CONNER, E.A. \& Miller, J.W. (1973) Factors affecting the production and accumulation of uterine luminal fluid in the rat. J. Pharm. exp. Ther. 184, 285-290.

HugGins, C. \& JENSEN, E. V. (1955) The depression of estrone induced uterine growth by phenolic estrogens with oxygenated functions at position 6 or 16: the impeded estrogens. J. exp. Med. 102, 335.

JoNEs, G. (1971) The synthesis and biological evaluation of a conformationally flexible oestrogen analogue. J. chem. Soc. 5, 922-925.

Josimovich, J.B., MinTz, D.H. \& Finster, J.L. (1967) Estrogenic inhibition of growth hormone-induced tibial epiphyseal growth in hypophysectomized rats. Endocrinology 81, 1428-1430.

Megliol, G. (1974) Uterine secretion in the intact rat and its property of dispersing corona cells in vitro. J. Steroid Biochem. 5, 384, Abstr.
Meglioli, G. \& Desaulles, P.A. (1973) The role of the pituitary in modifications of the uterine secretion of spayed, oestradiol-primed rats. Hormone Res. 4, 367-375.

Meglioli, G., Kalvoda, J. \& Desaulles, P.A. (1973) Effects of progestogenic substances on the uterine secretion of spayed rats primed with oestradiol. Hormone Res. 4, 97-106.

Meglioli, G., Krähendühl, C. \& Desaulles, P.A. (1969) The action of sex hormones on endometrial secretion in spayed rats sensitized to oestradiol. Experientia 25, 194-195.

RINGLER, I. (1961) The composition of rat uterine luminal fluid. Endocrinology 68, 281-291.

Velardo, J.T. (1951) Steroid hormones and uterine growth. Ann. N.Y. Acad. Sci. 75, 441-462.

ZONDEK, B. (1936) Impairment of anterior pituitary functions by follicular hormone. Lancet ii, 842847.

Received 12 August 1975 